\title{
Frações na Formação Continuada de Professoras dos Anos Iniciais: fragmentos de uma complexidade
}

\author{
Fractions in the Continuing Formation of Teachers of the Early Years: \\ fragments of a complexity
}

\author{
Luciane Ferreira Mocrosky* \\ ORCID iD 0000-0002-8578-1496 \\ Nelem Orlovski** \\ ORCID iD 0000-0002-1426-9671 \\ Simone Danielle Tychanowicz ${ }^{* * *}$ \\ ORCID iD 0000-0002-3770-6715 \\ Salete Pereira Andrade ${ }^{* * * *}$ \\ ORCID iD 0000-0002-2314-2322 \\ Maria Lucia Panossian ${ }^{* * * * *}$ \\ ORCID iD 0000-0001-5847-4485
}

\begin{abstract}
Resumo
Este artigo apresenta aspectos de uma pesquisa qualitativa, de abordagem fenomenológica, desenvolvida no âmbito da formação continuada de professores de Matemática. Expõe-se, aqui, um viés da formação que reconhece o estranhamento docente como elemento desencadeador do movimento formativo de dezesseis professoras, ao tematizarem frações como conteúdo escolar. A análise está pautada na possibilidade formativa de um encontro de quatro horas, que teve como ponto deflagrador as perplexidades das docentes ao se colocarem na escuta do que é

\footnotetext{
* Doutora em Educação Matemática, Univesidade Estadual Paulista (UNESP-RC). Professora da Universidade Tecnologica Federal do Paraná ( UTFPR, Curitiba), docente do Programa de Pós-Graduação em Formação Científica, Educacional e Tecnológica (PPGFCET-UTFPR) e do Programa de Pós-Graduação em Educação em Ciências e em Matemática (PPGECM-UFPR). Curitiba, Paraná, Brasil. Endereço para correspondência: Rua Luciano Hella, 252, casa 1, Campina do Siqueira, Paraná, Brasil, CEP: 80740-610. E-mail: mocrosky@ gmail.com. ${ }^{* *}$ Doutoranda do Programa de Pós-Graduação em Formação Científica, Educacional e Tecnológica (PPGFCETUTFPR ). Mestra em Educação Matemática, Universidade Federal do Paraná (UFPR). Professora da Rede Municpal de Ensino de Curitiba (RME), Curitiba, Paraná, Brasil. Endereço para correspondência: Rua João Bettega, 644, Bloco3, ap 604, Portão, Curitiba, Paraná, Brasil, CEP: 81070-000. E-mail: orlovskice@yahoo.com.br.

*** Mestra em Educação Matemática, Universidade Federal do Paraná (UFPR). Professora da Rede Municpal de Ensino de Araucária (RME), Araucária. Endereço para correspondência: Rua João Bettega, 644, Bloco3, ap 604, Portão, Curitiba, Paraná, Brasil, CEP: 81070-000. E-mail: simdanielle @ gmail.com. Ensino de Curitiba (RME), Curitiba, Paraná, Brasil. Endereço para correspondência: Rua Batista da Costa, 1030, Xaxim, Curitiba, Paraná, Brasil, CEP: 81810-190. E-mail: saletean @ terra.com.br.

****** Doutora em Educação, Universidade de São Paulo (USP). Professora da Universidade Tecnologica Federal do Paraná ( UTFPR, Curitiba), docente do Programa de Pós-Graduação em Formação Científica, Educacional e Tecnológica (PPGFCET-UTFPR) e do Programa de Pós-Graduação em Educação em Ciências e em Matemática (PPGECM-UFPR). Curitiba, Paraná, Brasil. Endereço para correspondência: Rua Eugênio José de Souza, 993, ap. 401, Água Verde, Curitiba, Paraná, Brasil, CEP: 80610-080. E-mail: mlpanossian@utfpr.edu.br.
}

***** Mestra em Educação Matemática, Universidade Federal do Paraná (UFPR). Professora da Rede Municpal de
\end{abstract}


familiar a cada uma ao serem perguntadas sobre o que entendem por fração. Numa postura fenomenológica, destaca-se o estranhamento como uma atitude filosófica que movimentou a formação, possibilitando que emergissem questionamentos sobre o conteúdo escolar e seu ensino. Nessa perspectiva, aponta-se o 'dar-se conta' das professoras sobre o predomínio da técnica e nomenclaturas formais, com as quais se lançaram à atribuição de significados de fração, tendo como proposta a localização em uma reta numérica. $O$ estudo revelou a importância de um estilo de formação em que o professor é chamado pelas inquietações que comparecem no diálogo com seus pares. Estilo, este, que considera a técnica didática, valendo-se de uma reorientação do modo de pensar, sentir e conceber o mundo, dada a incerteza de aprender a cada dia a ser professor.

Palavras-chave: Formação de Professores. Anos Iniciais. Frações. Fenomenologia.

\begin{abstract}
This work presents aspects of a qualitative research, of phenomenological approach, developed in the scope of the continuous formation of Mathematics teachers. Here, we present a training bias that recognizes teachers' estrangement as a triggering factor for the formative movement of sixteen teachers, in the theme of fractions as a school content. The analysis is based on the formative possibility of a four-hour meeting, which had as a starting point the perplexities of the teachers when they were asked what is familiar to each one of them when talking about the understanding of fraction. In a phenomenological posture, estrangement stands out as a philosophical attitude that moved the formation, allowing the arising of questions about school content and its teaching. In this perspective, the teachers' "realization" about the predominance of the technique and formal nomenclatures, with which they were launched to the attribution of fractional meanings, having as proposal the location in a number line. The study revealed the importance of a formation style in which the teacher is called by the anxieties that appear in the dialogue with their peers. Style, which considers the didactic technique, using a reorientation of the way of thinking, feeling and conceiving the world, given the uncertainty of learning each day how to be a teacher.
\end{abstract}

Keywords: Teacher Education. Early Years. Fractions. Phenomenology.

\title{
1 Introdução
}

Como pesquisadoras no campo da Educação Matemática, vimos nos dedicando mais especificamente à formação de professores que ensinam Matemática em qualquer trajeto formativo da Educação Básica. Neste cenário, a temática dos Anos Iniciais vem sendo discutida e estudada por nós sob diferentes perspectivas, destacando-se, no momento, os encontros de formação com docentes da rede pública de ensino no estado do Paraná.

Neste texto ${ }^{1}$ será abordado um viés da formação continuada nos Anos Iniciais, em um episódio com professores atuantes nos $4^{\circ}$ e $5^{\circ}$ anos do Ensino Fundamental. Explicitaremos compreensões-interpretações do encontro formativo ocorrido em 2015 e aspectos que sinalizam diferentes modos de pensar o ensino de frações, objetivando expor o movimento reflexivointerpretativo realizado no Grupo de Estudos e Pesquisa em Formação de Professores (GEForProf) acerca da temática das frações na formação continuada de professores dos Anos Iniciais.

Traremos, inicialmente, os encaminhamentos metodológicos do estudo. A seção

\footnotetext{
${ }^{1}$ Uma versão preliminar deste texto foi apresentada no V Simpósio Nacional de Ensino de Ciência e Tecnologia (V SINECT) (MOCROSKY et al., 2016)
} 
seguinte se dedica a revisar aspectos referentes à atual abordagem das frações, seu ensino e aprendizagem nos Anos Iniciais, na visão de pesquisadores que investigam o tema. $\mathrm{Na}$ sequência, abriremos um novo tópico para dizer do estranhamento com algo que nos move à compreensão. Por fim, apresentamos nosso estudo interpretativo ao estarmos com professores que, em formação, terão no horizonte o ensino de frações, solicitado no diálogo sobre o que é familiar no cotidiano escolar e como os estranhamentos vêm comparecendo.

\section{Aspectos metodológicos do estudo}

Os momentos de formação continuada com professores dos Anos Iniciais fazem parte de uma agenda a partir da qual as pesquisadoras atuam nas redes municipal e estadual de ensino, em Curitiba e Araucária, no Paraná ${ }^{2}$. No encontro com docentes, procura-se evidenciar as temáticas a serem trabalhadas, sendo estas previamente estabelecidas, conforme a necessidade explicitada pelos/as cursistas nas avaliações dos trajetos formativos anteriores.

Dos tópicos destacados nos encontros em 2015, com profissionais que tinham em seu horizonte ensinar Matemática às crianças dos Anos Iniciais do Ensino Fundamental, mais especificamente os que se dedicam ao trabalho com o ciclo II $-4^{\circ}$ e $5^{\circ}$ anos, as frações estiveram em destaque, solicitando estudos sobre o tema.

Todos os encontros formativos em que o GEForProf atua são registrados, ora com gravação de áudio, de vídeo, ora somente com as produções escritas dos participantes. A variedade ocorre conforme o interesse de estudos das discussões entre os envolvidos e com a devida autorização de todos. De qualquer modo, quando o interesse investigativo é conhecer o que acontece no encontro professor-aluno-conteúdo-aula ou o modo como nossos pares vêm compreendendo aspectos do ensino e do seu fazer pedagógico, assumimos o compromisso de manter o anonimato das pessoas para que elas possam se mostrar com mais naturalidade. Fazemos assim, também, por entendermos que o mais importante em nossas pesquisas no grupo é o revelado pelos participantes. Assim, assumimos que o importante é o dito e não quem disse.

O episódio formativo trazido neste texto vem do registro das expressões por escrito, em

\footnotetext{
${ }^{2}$ As pesquisadoras participavam das equipes formativas dos munícipios de Curitiba e Araucária no ano de 2015, bem como do grupo de pesquisa referido no texto. A agenda citada trata-se de um cronograma estabelecido anualmente pelos municípios com programas de formação continuada ofertados a todos os professores das duas redes de ensino. As temáticas seguem pesquisas realizadas nas próprias redes de ensino, buscando oferecer ações formativas de acordo com os interesses demonstrados pelos professores nessas pesquisas. Assim, anualmente os municípios organizam um cronograma de formação, com ações pontuais, tais como oficinas, semana de estudos pedagógicos, cursos longos, palestras e eventos. As pesquisadoras, como atuantes nas secretarias de educação dos municípios, também participaram da elaboração e execução dessas ações. No caso do episódio descrito, trata-se de uma "oficina" com a temática frações, com a carga horária de quatro horas ofertada aos professores atuantes $\operatorname{nos} 4^{\circ}$ e $5^{\circ}$ anos do município de Araucária.
} 
vídeo e em voz de um encontro de quatro horas realizado com 16 professoras do munícipio de Araucária, no ano de 2015, atuantes nos $4^{\circ}$ e $5^{\circ}$ anos do Ensino Fundamental. Do conteúdo produzido por filmagem ou gravação de áudio, realizamos a transcrição e transformamos o dito em um texto descritivo sobre a experiência exposta. Assim, lançamo-nos na discussão interpretativa-reflexiva do comunicado, de modo a destacar trechos significativos ao pesquisado, ao interrogado como fenômeno educativo, como nos orienta Bicudo $(2010 ; 2011)$.

Neste artigo, apresentamos um viés da formação que reconhece o estranhamento docente como um elemento desencadeador deste movimento formativo das professoras dos Anos Iniciais ao tematizarem frações como conteúdo escolar. Assim, nossa intencionalidade está orientada para o modo como o encontro de formação ocorreu, para o planejado, e como isso se mostrou significativo pelos aspectos formativos para nós e nossos pares, professores em formação.

Isso quer dizer que não realizamos uma análise das professoras em formação com base em suas expressões, mas, com uma postura fenomenológica de análise, refletimos sobre as possibilidades de um conteúdo dos Anos Iniciais, as frações, desencadearem um processo reflexivo entre professores em formação. Ao nos debruçarmos a compreender esse movimento formativo, nos demos conta do estranhamento como algo característico de uma atitude filosófica.

Pela opção explicitada, também destacamos que as falas aqui trazidas ao longo do texto não foram denominadas com códigos, uma vez que nosso interesse é de uma análise do encontro e de como ele foi movimentado pelas professoras.

A metodologia utilizada na elaboração desse texto orienta-se pela postura fenomenológica, cujos dados se originam das discussões conduzidas no grupo de estudo, junto aos acontecimentos que se destacam nos encontros de formação.

Inicialmente, nossa exposição parte do fundo teórico-metodológico trazido por pesquisadores que investigam o ensino da Matemática e que discorrem sobre as frações, procurando destacar as marcas desse ensino. Na sequência, nos lançamos a compreender a formação docente, transitando entre o familiar e o estranho para aquele que tem em seu cotidiano os pares professor-aluno, aluno-conteúdo, professor-professor.

\section{Fragmentos que expressam complexidades: o que se mantém na pesquisa acerca das frações nos Anos Iniciais?}

Nos Anos Iniciais do Ensino Fundamental, as frações têm sido apontadas como um assunto que gera dificuldades, tanto para o ensino, como para a aprendizagem (BERTONI, 
2004, 2009; ZONTINI, 2014; ONUCHIC; ALLEVATO, 2008; CAVALCANTI; GUIMARÃES, 2008).

Na literatura estudada, alguns autores (BERTONI, 2009; ONUCHIC; ALLEVATO, 2008) expõem a necessidade do ensino que se paute no conceito de fração. Mas, qual é o conceito de fração? O que significa conceito para esses autores? Sobre isso, grande parte deles diz ser a variedade de significados que a elas podem ser atribuídos. Bertoni (2009) resume alguns aspectos iniciais para o trabalho na escola, pontuando fração e número fracionário, tomando por contexto os números racionais, que têm expressão fracionária e decimal:

Fração: representa tanto certas partes da unidade, quanto o registro numérico associado a essas partes.

Número fracionário: É o número, único (embora com várias representações) associado a toda uma classe de frações equivalentes (BERTONI, 2009, p. 12).

Contribuindo com as discussões, Onuchic e Allevato (2008) apresentam um estudo sobre o ensino de números racionais conduzidos metodologicamente pela "resolução de problemas". As autoras não focam nos Anos Iniciais, mas expõem compreensões que podem ser trazidas a esse nível de ensino ao se pensar no número racional e suas "personalidades". Afirmam que na comunidade de educadores matemáticos tais números trazem desconforto, tanto a professores, como a alunos, e tal desconforto é fruto da dificuldade que elas explicitam ser de natureza diversa. Uma delas, por exemplo, é o sentido que $\frac{2}{3}$ faz quando, num lance de olhar, o que pode ficar em destaque são os números 2 e 3 . Outra dificuldade é fruto da multiplicidade de significados desses números. As autoras enfatizam que não há um consenso sobre melhores estratégias para o ensino, mas afirmam que um bom começo para o trabalho está em trazer com clareza significados compreendidos.

Onuchic e Allevato (2008) sugerem o trabalho com situações problematizadoras, pois estas solicitam a mobilização de conhecimentos que permitem destacar as diferenças entre os números racionais em contextos diversos.

Como muitas situações cotidianas exigem compreensões de números racionais — como, por exemplo, elaborar uma receita culinária, medir e cortar tecidos para a confecção de roupas, saber a probabilidade de um evento ocorrer —, as autoras apostam no problema como deflagrador para a construção da ideia de racional que será mobilizada para a sua resolução. Com esse intuito, apresentam uma série de situações para problematizar a diversidade de entendimentos que pode aparecer na resolução de problemas e sugerem que esse encaminhamento pode favorecer o ensino que visa fazer sentido ao aluno. Pautadas no texto de Onuchic e Allevato (2008), elaboramos um quadro (Quadro 1) simplificado com as exposições das personalidades do número racional. 


\begin{tabular}{|c|c|c|}
\hline $\begin{array}{l}\text { Personalidade do } \\
\text { número racional }\end{array}$ & Problema & Significado \\
\hline Ponto racional & Localize na reta numérica os números: $\frac{1}{2}, \frac{2}{3}$ & $\begin{array}{l}\text { Todo número racional "ocupa um ponto } \\
\text { bem definido na reta e, reciprocamente, a } \\
\text { todo ponto racional da reta corresponde um } \\
\text { número racional". }\end{array}$ \\
\hline Quociente & $\begin{array}{l}\text { Três pizzas devem ser divididas igualmente } \\
\text { entre cinco pessoas. Quanto de pizza cada } \\
\text { pessoa comerá? }\end{array}$ & $\begin{array}{l}\text { Um número de objetos precisa ser } \\
\text { repartido igualmente num certo número de } \\
\text { grupos. }\end{array}$ \\
\hline Fração & $\begin{array}{l}\text { Jô, Pat e Cris resolveram fazer um piquenique } \\
\text { e combinaram levar sanduíches para o almoço. } \\
\text { Jô levou } 3 \text { sanduíches, Pat levou } 2 \text { e Cris se } \\
\text { esqueceu do combinado e não levou sanduíche } \\
\text { algum. Assim, resolveram repartir os } \\
\text { sanduíches que tinham levado igualmente entre } \\
\text { as três, mas cobraram de Cris } \mathrm{R} \$ 5,00 \text { por sua } \\
\text { parte. Que parte dos } \mathrm{R} \$ 5,00 \text { recebeu Jô? E Pat? }\end{array}$ & $\begin{array}{l}\text { Surge a fração, que é uma relação da parte } \\
\text { com o todo e a representação pictórica. } \\
\text { Envolve, também, a ideia de quociente. }\end{array}$ \\
\hline Operador & $\begin{array}{l}\text { Represente geometricamente } \frac{2}{3} \text { de quatro } \\
\text { maneiras diferentes. }\end{array}$ & $\begin{array}{l}\text { O operador tem significado semelhante ao } \\
\text { de "encolher" ou "esticar", de "reduzir" ou } \\
\text { "ampliar". [...] O operador define uma } \\
\text { estrutura multiplicativa de números } \\
\text { racionais. }\end{array}$ \\
\hline Razão & $\begin{array}{l}\text { Duas jarras iguais contêm misturas de álcool e } \\
\text { água nas razões de } \frac{3}{5} \text { (três para cinco), na } \\
\text { primeira jarra e } \frac{3}{7} \text { (três para sete) na segunda. } \\
\text { Juntando-se os conteúdos das duas jarras, qual } \\
\text { será a razão entre álcool e água na mistura } \\
\text { resultante? }\end{array}$ & $\begin{array}{l}\text { Razão é uma comparação multiplicativa } \\
\text { entre duas grandezas } \\
\quad(a: b \text {, a está para b). } \\
\text { A razão é fundamental para a compreensão } \\
\text { de proporcionalidade. }\end{array}$ \\
\hline Proporcionalidade & $\begin{array}{l}\text { Se com } 3 \text { dólares podiam-se comprar duas } \\
\text { libras esterlinas, quantas libras poderiam ser } \\
\text { adquiridas com } 21 \text { dólares? }\end{array}$ & $\begin{array}{l}\text { Proporcionalidade: } \\
\text { Comparação multiplicativa. }\end{array}$ \\
\hline
\end{tabular}

Quadro 1 - Personalidades do número racional

Fonte: Elaboração das autoras baseadas em Onuchic; Allevato, (2008).

Como apontam Onuchic e Allevato (2008), o fato de termos a fração como um aspecto dos números racionais não ameniza as complexidades, pois a estas também pode-se atribuir uma multiplicidade de significados.

E os Anos Iniciais? A orientação é que as frações estejam presentes nas atividades escolares desde o segundo ano do Ensino Fundamental, iniciando com as ideias de metade e avançando nos anos subsequentes. Conforme os Parâmetros Curriculares Nacionais (PCNs), somente no segundo ciclo ${ }^{3}$ dos Anos Iniciais devem ter como objetivo "construir o significado do número racional e de suas representações (fracionária e decimal), a partir de seus diferentes

\footnotetext{
${ }^{3} \mathrm{O}$ segundo ciclo em 1997, quando os PCN foram divulgados correspondia a $3^{\mathrm{a}}$ e $4^{\mathrm{a}}$ série, que hoje correspondem ao $4^{\circ}$ e $5^{\circ}$ ano. Atualmente está vigente a Base Nacional Comum Curricular (BNCC) que também apresenta a introdução dos números racionais, bem como sua representação a partir do $4^{\circ}$ ano do Ensino Fundamental
} 
usos no contexto social" (BRASIL, 1997, p. 55). Entretanto, há o reconhecimento de que "como neste ciclo trabalha-se apenas com os naturais e ainda não com os inteiros negativos, os números racionais a serem tratados são quocientes de números naturais” (BRASIL, 1997, p. 67), questão esta apontada nos estudos de Onuchic e Allevato (2008).

Bertoni (2004) diz que, no início da escolaridade, há um trabalho introdutório, portanto não se pode esperar que a criança que está aprendendo um vocabulário nomeie alguma fração, compreenda a representação pictórica das unidades e os aspectos das relações estabelecidas entre o todo e as partes, ou parte-todo, bem como que tenha compreendido o que é uma fração. Além disso, para o entendimento é importante "encontrar caminhos para levar o aluno a identificar quantidades fracionárias em seu contexto cotidiano e apropriar-se da ideia do número fracionário correspondente, usando-os de modo significativo" (BERTONI, 2009, p. 16).

Contribuindo com o ensino nos Anos Iniciais, Cavalcanti e Guimarães (2008) buscam explicitar compreensões sobre as personalidades de fração, de modo a orientar o trabalho de análise de questões expostas em livros didáticos destinados a este público. As autoras afirmam que, na literatura, não há um padrão que configure tais significados e, para dar clareza, expõem uma compreensão tal como é expressa na Figura 1.

\begin{tabular}{|c|c|c|}
\hline Significado & Definição & Exemplo \\
\hline Parte/todo & $\begin{array}{l}\text { Partição de um todo em } n \text { partes } \\
\text { iguais, em que cada parte pode } \\
\text { ser representada como } 1 / n \text {. Um } \\
\text { procedimento de dupla } \\
\text { contagem, das partes do todo e } \\
\text { das partes tomadas, no geral, è } \\
\text { o suficiente para solucionar o } \\
\text { problema. }\end{array}$ & $\begin{array}{l}\text { Uma jarra com suco foi } \\
\text { dividida entre } 3 \text { copos. Joăo } \\
\text { bebeu um copo. Que fraçăo } \\
\text { representa o que ele bebeu } \\
\text { da jarra? }\end{array}$ \\
\hline Quociente & $\begin{array}{l}\text { A fraçăo indica uma divisão e } \\
\text { seu resultado. Nas situaçōes de } \\
\text { quociente, temos duas variáveis, } \\
\text { sendo que uma variável } \\
\text { corresponde ao numerador e a } \\
\text { outra ao denominador. }\end{array}$ & \begin{tabular}{|l} 
Em uma festa foram \\
distribuidos 2 bolos para 6 \\
crianças \\
Quanto cada uma valmente. \\
receber?
\end{tabular} \\
\hline Probabilidade & $\begin{array}{l}\text { A fraçăo representa a chance de } \\
\text { um evento ocorrer. (numero de } \\
\text { casos favoráveis dividido pelo } \\
\text { número de casos possiveis). }\end{array}$ & $\begin{array}{l}\text { Jogando uma vez um dado } \\
\text { que fraçăo representa a } \\
\text { possibilidade de tirar o } \\
\text { número } 3 \text { ou 4? }\end{array}$ \\
\hline $\begin{array}{l}\text { Operador } \\
\text { multiplicativo }\end{array}$ & $\begin{array}{l}\text { A fração é um valor escalar } \\
\text { aplicado a uma quantidade, ou } \\
\text { seja, um multiplicador da } \\
\text { quantidade indicada. }\end{array}$ & $\begin{array}{l}\text { Numa jarra contendo } 900 \mathrm{ml} \\
\text { de suco Pedro bebeu } 1 / 3 \\
\text { do liquido. Quantos } \\
\text { mililitros ele bebeu? }\end{array}$ \\
\hline Número & $\begin{array}{l}\text { A fração é um número em si, não } \\
\text { sendo necessário que expresse } \\
\text { uma relaçăo ou contexto para } \\
\text { ser compreendida numa dada } \\
\text { situaçăo. }\end{array}$ & $\begin{array}{l}\text { Onde posso marcar na reta } \\
\text { numérica } 1 / 3 \text { ? }\end{array}$ \\
\hline Medida & $\begin{array}{l}\text { Comparaçăo na qual a fraçăo } \\
\text { está relacionada a pergunta } \\
\text { quantas vezes? Neste caso, uma } \\
\text { determinada parte é tomada } \\
\text { como referência para se medir } \\
\text { uma outra. }\end{array}$ & $\begin{array}{l}\text { Tomando a reta CD como } \\
\text { unidade de medida, quanto } \\
\text { mede AB? } \\
\text { A_B } \\
\text { Outro caso: Quantos copos } \\
\text { de } 1 / 3 \text { litro são necessários } \\
\text { para encher um balde de } \\
15 \text { litros? } \\
\end{array}$ \\
\hline Razăo & $\begin{array}{l}\text { A fração refere-se a quantidades } \\
\text { intensivas, nas quais a } \\
\text { quantidade é medida pela } \\
\text { relaçăo entre duas variáveis. }\end{array}$ & $\begin{array}{l}\text { Para fazer um suco de } \\
\text { laranja eu misturo numa } \\
\text { jarra } 2 \text { copos de água para } \\
1 \text { de concentrado. Que } \\
\text { fraçăo de concentrado eu } \\
\text { tenho na jarra? }\end{array}$ \\
\hline
\end{tabular}

Figura 1 - Frações e significados

Fonte: CAVALCANTI; GUIMARÃES, (2008, p. 2-3). 
Cavalcanti e Guimarães (2008) enfatizam a importância de ter claros os significados que, mobilizados em sala de aula, servem não para engessar modos de compreender as frações, mas para balizar a atividade docente. Sobre isso, relatam que, na literatura, um mesmo problema traz abordagens de análise diferenciadas. Isso se deve ao fato de que no trabalho com a resolução de problemas, cada um articula seus conhecimentos e estratégias, revelando caminhos que possibilitam evidenciar significados diferentes para lograr êxito no problema proposto.

Romanatto, em 1999, já vinha anunciando as constatações expostas pelos pesquisadores mencionados. Considera, assim, que os números racionais precisam ser compreendidos na Educação Básica como uma "teia de relações" em diferentes contextos, tais como medida, quociente, razão, operador multiplicativo, probabilidade e número.

[...] o mais importante seria deslocarmos a atenção dos objetos em si para as relações que esses objetos podem representar ou para as relações que podem ser construídas ou adquiridas com tais objetos em seus mais variados contextos de significação (ROMANATTO, 1999, p. 39).

Notadamente, vários pesquisadores se debruçam em estudos relacionados ao ensino de frações situadas na formação de professores. Moreira (2004) explicita que os professores reconhecem a complexidade, mas, sobre o ensino, concebem-no de maneira muito simples, nem sempre dando a devida atenção a este conteúdo escolar. Na mesma direção está a pesquisa de Damico (2007), que constatou que professores e alunos apresentam uma visão dispersa sobre os racionais, priorizando os aspectos processuais em relação aos conceituais. Tal visão é atribuída pelo próprio autor ao nível de conhecimento didático, relacionado às formas de apresentação das frações, o que Esteves e Souza (2012) também concluíram em estudo desenvolvido com docentes.

Parte-todo tem sido a abordagem predominante nos Anos Iniciais. A partir da divisão de figuras geométricas planas em partes iguais é dado início ao ensino que tem em sua sequência as operações. Sobre isso, Nunes e Bryant (1997) destacam a elaboração e realização de percursos pedagógicos como frágeis para a aprendizagem, pois deixam uma falsa ideia de compreensão. Relacionando ao que preconiza Silva (2005), os professores constroem estruturas rígidas para os números fracionários, sobretudo priorizando a concepção de parte-todo em contexto de superfícies. Tal concepção se realiza pela dupla contagem das partes e, segundo Canova (2006), Campos, Magina e Nunes (2006) e Merlini (2005), é usada sem considerar a conservação da área da figura.

Nos cadernos de formação do pró-letramento em Matemática, Lins e Silva (2008) preparam o solo para a formação de professores e explicitam que um aprofundamento sobre frações deve incluir os significados das palavras numerador e denominador, que estão 
intimamente ligados a medidas. Os pesquisadores exemplificam:

Quando dizemos que o comprimento de uma mesa é dois metros, estamos indicando o "quanto" (dois) e o de que "tipo" (metro). Se mudarmos o "tipo" para centímetro, o "quanto" teria que mudar para 200 para a medida ficar certa, já que $2 \mathrm{~m}=200 \mathrm{~cm}$. Assim, uma das formas de se entender o que é uma fração, é que elas são o resultado de se medir alguma coisa, usando como referência uma parte da unidade (LINS; SILVA, 2008, p. 10).

Os pesquisadores se valem da medida para falar de frações usando o exemplo: "Imaginemos que pessoas comeram uma parte da torta [...], e restou o que está indicado. Como representar, com um número, o tanto que foi comido?” (LINS; SILVA, 2008, p.10).

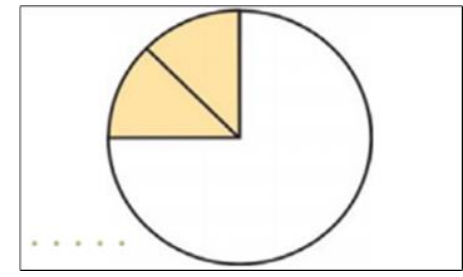

Figura 2 - Torta com pedaços comidos

Fonte: Lins e Silva (2008, p.10).

Lins e Silva (2008) afirmam ser importante medir escolhendo-se uma unidade. No caso, os alunos podem lançar mão de várias possibilidades, uma delas é tomar $\frac{1}{8}$ como a medida a saber quantas vezes cabe na parte comida. Daí, decorre 6 vezes a unidade $\frac{1}{8}$. Por aí há um encaminhamento possível para a constituição do sentido de fração como um número.

Os autores com os quais dialogamos mostram-nos o que vem se mantendo na compreensão de professores quando perguntados sobre frações. "Na verdade, há muita coisa poluindo e escondendo o cristal puro que fração é: um número. Uma ideia matemática associada à quantificação" (BERTONI, 2009, p. 12). Com esse entendimento, abrem-se a nós questionamentos sobre possibilidades de trazer o tema frações para a formação de professores que ensinam Matemática, colocando em debate entre pares, professores e alunos, algumas compreensões familiares pelo cotidiano vivido e alguns estranhamentos que brotam dessa familiaridade quando se interroga o ensino e os modos de ensinar, a aprendizagem e modos de aprender, enfim, o entrelaçamento dos significados para que o sentido vá se fazendo a cada um.

\section{0 estranhamento}

No estranhamento, o que se abre a nós?

Nossos hábitos vêm automaticamente, não percebemos. Para ressuscitar nossa percepção das coisas, existe a Arte, cujo propósito é nos dar a sensação da coisa: sensação que deve ser de visão e não de reconhecer. $\mathrm{O}$ olhar procura aquilo que ele quer ver. Isso tem que ser usado como instrumento do conhecimento. A Arte usa o 
estranhamento das coisas, no sentido de abrir-se para nós. Costuma-se dizer que a Matemática não permite a abertura, mas a Matemática também é aberta para a interpretação - a atividade dos homens é determinada pelas palavras e não pelos fatos -, e provoca possibilidades (LONGARETTI, 2005, p. 38).

Compreendemos o estranhamento como algo característico de uma atitude filosófica, assim como a indagação, a argumentação e a reflexão. $\mathrm{O}$ estranhamento acontece quando uma pessoa vivencia uma circunstância diferente da que costuma experimentar cotidianamente ou, quando no viver com o familiar, algo lhe salta aos olhos, provocando estranheza. Perplexos, ficamos em estado de alerta, atentos às coisas de modo a observarmos algo que antes não víamos ou que não nos causava incômodo. No estranhar-se com e nas coisas, questionamos o visto, que sempre é observado por alguém, de onde se entende o estranhamento como algo genuíno, dada a singularidade de cada um.

A palavra estranho vem do latim extraneu e faz referência ao exterior; que não pertence à família (CUNHA, 2010). Entendemos o estranhamento como uma forma possível e singular de nos darmos conta e nos vermos no mundo como o que o constitui. Ao sermos provocados pelo estranhamento, percebemos o mundo de outras perspectivas, originando diferentes formas e ações, ou ainda um modo possível de mantermo-nos em formação. Tal formação consiste num modo singular de se estar em movimento, dando forma a um modo de ser professor, de maneira a estar sempre em busca da condição de ser na forma ideal, revelada pelo professor real. Ser professor é um desafio que se impõem a cada momento, a cada aula. É o quanto estamos preparados para a atividade docente, que deságua no quanto estamos prontos para a aula.

No cotidiano do professor, o estranhamento vem acompanhado de questões e muitas delas emergem do ensinar e do refletir sobre o que é e como foi ensinado. No dia a dia da sala de aula assumem-se as frações como algo comum e familiar, mas, no demorar-se pensando o trabalho realizado e seus possíveis significados, vem a estranheza.

\subsection{Do familiar ao estranho: o que é uma fração?}

O conteúdo frações está disposto nos programas escolares, mais enfaticamente no $4^{\circ} \mathrm{e}$ $5^{\circ}$ anos do Ensino Fundamental. Nessa etapa escolar são identificados como conteúdos conceituais e procedimentais a comparação, a ordenação e a localização na reta numérica de números racionais na forma decimal, bem como o "reconhecimento de que os números racionais admitem diferentes (infinitas) representações na forma fracionária” (BRASIL, 1997, p. 59), além do reconhecimento de significados das frações em situações problema, como partetodo, quociente ou razão. Assim, um desafio para o professor que ali atua reside em significar 
as frações, em diferentes perspectivas, para que elas façam sentido às crianças.

Num encontro de formação com professoras do segundo ciclo, inicialmente lançamos o questionamento: “O que é fração?” e solicitamos que escrevessem em um papel o que compreendiam sobre o perguntado, sem a necessidade de identificação.

Ao serem perguntadas, sem a interferência de explicações ou sinalização de respostas desejadas, a intenção era provocar discussão com os pares e invocar cada uma a elaborar por escrito o que compreendem por frações. Dadas as calorosas discussões, entendemos ser o tema uma fonte inesgotável de dúvidas e incertezas: um desafio para o ensino.

As expressões das professoras em resposta à pergunta foram depositadas em uma urna e nada mais falamos sobre elas durante o encontro. O objetivo dessa proposta era trazer o que lhes era familiar, pelo seus modos de compreensão, e provocar estranheza e inquietação sobre os próprios sentidos que se fizeram acerca do diálogo com seus pares.

Dando continuidade à formação e atentas ao propósito de causar estranheza no que é familiar, optamos por tratar do que Onuchic e Allevato (2008) chamam "ponto racional" ao falarem das personalidades dos números racionais. Em seus estudos, estas pesquisadoras constataram que muitos professores têm dificuldade em identificar fração como um número. Desse modo, intencionamos trazer para a formação o conhecimento de número racional, propondo a identificação aproximada de $\frac{1}{3}$ na reta numérica real (Figura 3 ).

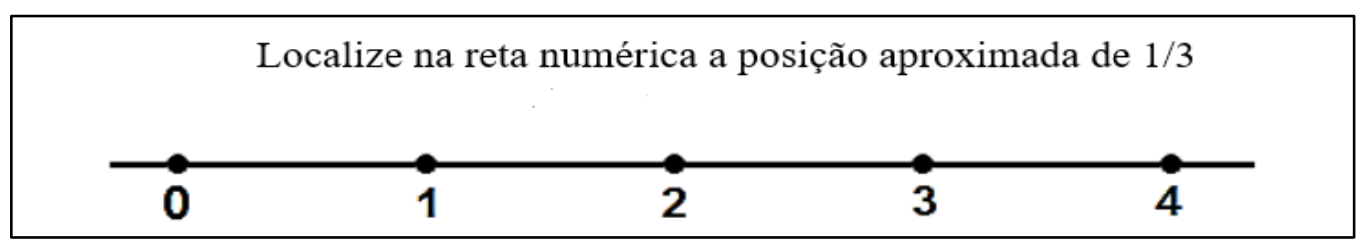

Figura 3 - Localização de um número na reta numérica Fonte: Acervo das autoras (2015).

Novamente muitas discussões se levantaram a respeito do que seria $\frac{1}{3}$. Na socialização entre as professoras para dar conta do perguntado, destacamos algumas falas:

-É pegadinha!

- Deu tilt!

- Do jeito que está a pergunta, está difícil, eu até cheguei a ler duas vezes, para ver se não era uma pegadinha: "Localize na reta numérica a posição aproximada do número 1/3".

- Não pode ser aí (...)

- (Risos) vergonha, vergonha...

— Não sei! (Gravação áudio-visual do diálogo entre as professoras, 2015).

A insegurança ganhou relevo nas falas. As tarefas matemáticas que vêm com enunciados, ao estilo de um problema, podem causar desconfiança quanto ao propósito e, consequentemente, insegurança. A expressão "ser pegadinha" é uma fala recorrente em 
momentos de formação de professores dos Anos Iniciais que vimos trabalhando. Pode nos indicar crença numa Matemática que engana, ilude e nos coloca em situações constrangedoras.

Avançando nas discussões, a inquietação foi desvelando o sentido que as professoras atribuíam à fração no exercício proposto:

- Se eu pegar a reta toda é aqui (...) [se referindo a um espaço entre o dois e o três], mas a medida é 0,9 .

— Não! A medida é $0,333 \ldots$

- Mas se você divide o 1 por 3 dá 0,333... Parece que é, porque não tem como dividir a reta.

- Não! é que aqui ela raciocinou como $\frac{1}{2}$, contou os espaços.

- Não! Tem que contar os espaços: 3 (...)

- Esse aqui é o numerador [referindo-se ao 1], esse aqui é o denominador [referindo-se ao 3]. É

o que divide as partes do todo. (Gravação áudio-visual do diálogo entre as professoras, 2015).

Tal tarefa já havia sido realizada por alunos do $5^{\circ}$ ano de uma das autoras. Aos estudantes havia sido proposto que localizassem na reta numérica a posição aproximada do número $\frac{1}{3}$ e justificassem a resposta. Continuando, apresentamos às professoras algumas expressões de alunos para que analisassem como estes se saíram na atividade proposta (Figura 4).

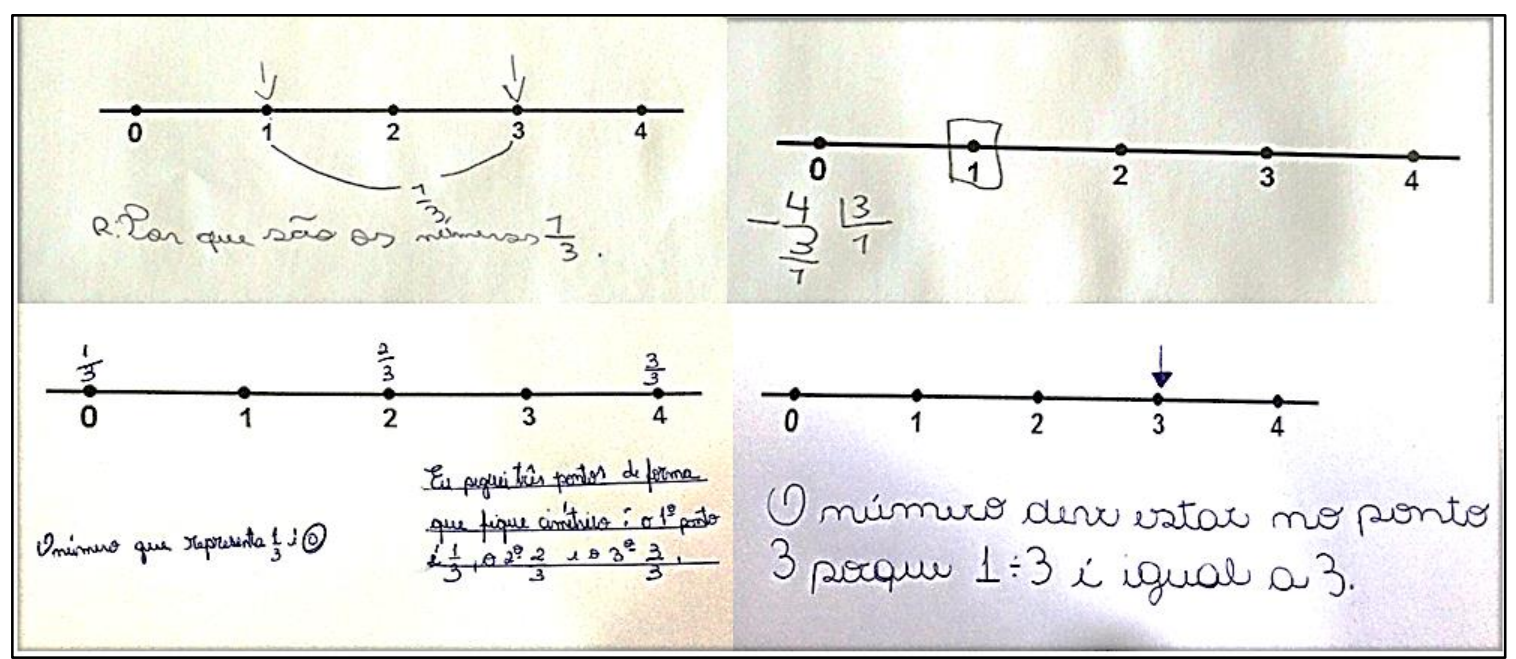

Figura 4 - Expressões de alunos para a localização de $\frac{1}{3}$ na reta real Fonte: Acervo das autoras (2015).

Escolhemos esta proposta pela possibilidade que tínhamos de trazer expressõescompreensões dos alunos quando a mesma questão foi apresentada a professores. Pensamos que esta ação poderia promover um encontro entre ensino e aprendizagem, em que os docentes, ao ouvirem e se demorarem nas expressões do compreendido pelos alunos, pudessem voltar à sua prática, ao seu saber sobre isso que se está ensinando. Seria uma abertura para que refletissem sobre o que os alunos estão compreendendo, já que o entendimento deles poderia expressar também a compreensão de alguns professores. A intenção era de uma exposição geral que contribuísse com a oportunidade de estranhar-se no modo como concebem o ensino e o 
conteúdo matemático a ser discutido.

As manifestações de alunos e professores mostram aspectos convergentes. Como exemplo, várias professoras pensaram em dividir a reta em três partes e marcar a primeira como resposta possível, assim como os alunos fizeram. Esse modo de proceder vai ao encontro da pesquisa de Onuchic e Allevato (2008), que apresenta a ideia tida por alguns professores de que "frações não são números". Segundo as autoras, este tipo de problema oportuniza o trabalho com a compreensão de que todo número racional $\frac{a}{b}$ ocupa um ponto bem "definido na reta e, reciprocamente, a todo ponto racional da reta corresponde um número racional" (ONUCHIC; ALLEVATO, 2008, p. 87), tal como vimos compreendendo no movimento de formação efetuado.

Pelos recortes das falas das professoras constatamos que a maioria associa à fração a ideia de partes de um todo, bem como a operação aritmética da divisão, constatação esta que se faz presente na literatura, exposta por muitos autores (ONUCHIC; ALLEVATO, 2008; BERTONI, 2009; ZONTINI, 2014).

Ao atentarem para a projeção de algumas respostas comunicadas por alunos, imediatamente as professoras expressaram seu espanto:

- Nossa!

- De onde ele tirou isso?

- Meu Deus! (Gravação áudio-visual do diálogo entre as professoras, 2015).

A atenção às resoluções dos alunos abriu um espaço para a discussão de diversos aspectos que permeiam o ensino das frações nos Anos Iniciais, juntamente à formação do professor em acontecimento. Nesse momento foram retomados aspectos estruturantes do conteúdo de frações, enfatizando com as docentes a importância de compreender os diferentes significados ocultados na representação fracionária, bem como a sua significância quando estão em discussão, via resolução de problemas.

Silva (2005) constatou em sua pesquisa como professores atuantes no $5^{\circ}$ ano do Ensino Fundamental constroem estruturas rígidas para organizar as atividades sobre frações com os alunos, sobretudo priorizando a concepção de parte-todo em contexto de superfícies, que se realiza pela dupla contagem das partes.

Um exemplo da dupla contagem em contextos de superfícies pode ser encontrado frequentemente em livros didáticos e em blogs de atividades utilizadas pelos professores (Figura 5): 


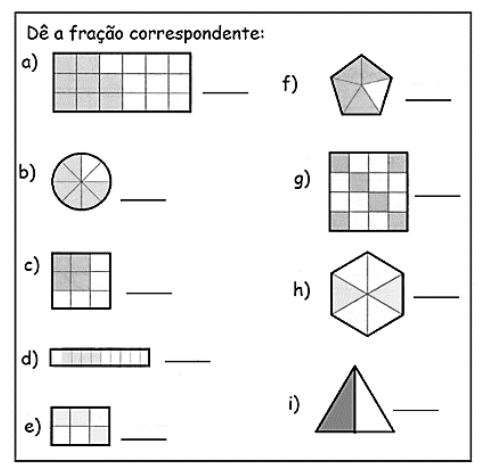

Figura 5 - Exercícios de dupla contagem Fonte: RERIDA MARIA, 2014.

Quando essas atividades são propostas, o que geralmente acontece é que o aluno apenas conta as partes em que o inteiro foi dividido: 18 (denominador) e, em seguida, conta quantas foram pintadas (quantas estão sendo consideradas: numerador): 8 , tendo assim, no item a, a fração $8 / 18$ como a fração correspondente. Porém, a relação entre essas partes se perde e a significação da fração como número acaba sendo comprometida.

A dupla contagem é evidenciada também em estudos, tais como realizados por Canova (2006), Bertoni (2009), Nunes et al. (2009), Merlini (2005), Gimenes e Bairral (2005) e Romanatto (1997). Tais dificuldades são decorrentes do fato de aplicarem o conhecimento que possuem sobre os números naturais, considerando a representação simbólica fracionária como dois números naturais um sobre o outro, em que um representa o total de partes e o outro as partes pintadas, tomadas. Tais pesquisas apontam que alunos utilizam essa mesma estratégia inadequada de realizar dupla contagem desconsiderando a conservação da área da figura, fato este que Canova (2006) constatou ocorrer entre os professores.

Esta estratégia pode ser considerada inadequada, pois descaracteriza a grandeza que está sendo medida, neste caso, a área. Também percebemos que há uma tentativa, por parte das professoras, de tratar o contínuo com o mesmo modo de pensar o discreto, questão esta que Silva (2005) denomina "discretização do contínuo". Discretiza-se a medida da superfície para que se possa quantificar, ou realizar a contagem. Mas o medir e o contar são processos diferentes. Na discretização do contínuo, o contínuo é dividido e perde o significado de sua grandeza (no caso, a medida da superfície) e se conta somente em quantas partes ele foi dividido. Já não importa se a grandeza era a medida da superficie, medida de capacidade, ou medida de tempo.

Essa foi a ideia manifesta na experiência de formação que conduzimos e as dificuldades ou a falta de clareza sobre o que fazer destacaram-se pela ideia da divisão em partes com um único significado, levando à impossibilidade de resolução da questão proposta imediatamente. 
Operar com algo, ter um resultado único, correto, ou ainda, aplicar uma suposta definição matemática que fosse adequada na situação era o esperado.

Assim como Damico (2007), que constatou a visão dispersa de alunos e professores sobre frações, Esteves e Souza (2012) encontraram na investigação realizada que os docentes têm dificuldades quanto à compreensão dos números racionais, mais especificamente à sua representação decimal. A principal dificuldade estava justamente em compreender as relações entre a representação decimal e a fracionária de um mesmo número racional, bem como a comparação e a ordenação de frações e números decimais.

\subsection{Do estranho ao familiar}

Como encontrar $\frac{1}{3}$ na reta real? Pode uma fração ser maior do que o todo? Estas perguntas ficaram pulsando no encontro formativo, enquanto as professoras compartilhavam seus conhecimentos sobre o tema em tela, tendo no horizonte expressões de alunos, conforme Figura 4.

- Não sei!

- Mas olha aqui: um terço, conta os espaços, divide.

- Não! Olha só, é 1 dividido por 3, que dá 0,333... uma dízima, isso tem que estar entre o zero e o um.

Mas, $\frac{1}{3}, \frac{2}{3}, \frac{3}{3}$ [a professora apontou para o espaço entre o 1 e o 3$] \ldots$

- Você está dividindo a reta em 3, veja eles pediram o número 1/3, é diferente. Se fosse pedido um percurso, dai dividiria em partes, pra saber o que foi percorrido.

- Do jeito que está a pergunta, está difícil, eu até cheguei a ler duas vezes, para ver se não era uma pegadinha: "Localize na reta numérica aproximadamente a posição do número $\frac{1}{3}$ ". É por isso que eu acho que tem que trabalhar mais a questão da linguagem, quando a gente trabalha com as crianças. O que eu vejo às vezes, localize $\frac{1}{3}$ na reta. E ai, $\frac{1}{3}$ do que? - Porque até a questão do $\frac{1}{3}$, pode ser $\frac{1}{3}$ de qualquer um daqueles espaços [se referindo aos intervalos, entre 1 e 2, 2 e 3, e 3 e 4]. Eu posso considerar cada um daqueles espaços como um inteiro, ou eu posso considerar a reta inteira como um inteiro, ou eu posso considerar até o 4 um inteiro. Então deixar claro isso, o que eu estou pedindo. É $\frac{1}{3}$ do quê?

- E é importante até para eles confrontarem essa questão do $0,333 \ldots$ e agora vamos fazer $\frac{5}{3}$, dá "um" vírgula alguma coisa (Gravação áudio-visual do diálogo entre as professoras, 2015).

Silva (2005) destaca ser muito comum o entendimento de frações como dois números naturais, e que o trabalho nos Anos Iniciais, deflagrado pela divisão de figuras e a expressão $\frac{a}{b}$ tem trazido grandes dificuldades para vê-la como um número completo em si, único que corresponde a algo, uma quantia ou uma localização na reta numérica.

- Então deixar claro isso, o que eu estou pedindo. É 1/3 do quê? (Gravação áudio-visual da fala de uma professora, 2015). 
Em meio às discussões, o grupo chega a um ponto de concordância — "É $\frac{1}{3} d o$ quê?" - sucitando que há um todo maior em que o todo e as partes estão inseridas. Brota, assim, a imprecisão em registrar o valor $\frac{1}{3}$ na reta real, principalmente se o foco estiver na representação decimal, como dízima periódica $(0,3333 \ldots)$. Tal constatação trouxe a importância do contínuo e do discreto, viés da formação que não será contemplado neste artigo, mas que mostra quão perplexas foram ficando as professoras, principalmente pelo desejo de se ocuparem com as frações como um objeto matemático em si.

Casanova (2006), ao analisar a obra "Ser e Tempo", de Martin Heidegger, explicita a questão da ocupação, dando como exemplo um objeto, um martelo. O que temos diante de nós não é a presença da coisa, do objeto que seja simplesmente o que existe em sua substância ou individualidade, que permanece. Ou seja, os objetos não nos aparecem como coisa fora de nós, mas ao aparecerem a nós, aparecem-nos simultaneamente num horizonte de ocupações relacionadas ao seu uso, que, ao se adequar neste momento, revela-o objeto como algo que tem uma serventia própria.

Podemos pensar no modo como ensinamos os números racionais nos Anos Iniciais unicamente pela perspectiva da ocupação, do ponto de vista do objetivamente dado, tomando a fração como um objeto em si mesmo.

Por exemplo, quando os professores pensam-na como as partes de um todo, como algo que está posto ao uso e o uso como se mostrou, associado a um meio para se conseguir um resultado, seria um fazer técnico. O que seria então este objeto? A fração? Se o pensarmos como algo fora, se nos colocarmos na frente dele e o olharmos como algo que já existe e permanece em sua concretude, nossa primeira reação é a de pensá-lo como algo absurdo, pois ao olhá-lo unicamente da perspectiva do objeto dado não conseguimos pensar nos sentidos ou significados de sua existência. Por isso, perguntamos aos professores: “o que é fração?”, com o intuito de provocá-los ao absurdo de se pensar um objeto matemático, em si mesmo, fora de nós e desprendido de um fundo. Nossa intenção voltou-se a colocar o outro (professor em formação) na condição de estranhar-se e, com isso, colocar-se em movimento de pensar sobre um ponto de vista diferente do que ele estava familiarizado.

O simplesmente saber o que é, ou para quê serve uma fração não explica como ela constituiu-se desta maneira e não de outra. Parte daí a necessidade da vivência de pensar na representação fracionária de um número racional em um contexto de localização na reta numérica. 
Por isso, segundo Heidegger (2005), não nos ocupamos dos objetos — neste caso, dos matemáticos - , como se eles fossem externos a nós, algo em separado. A ocupação se faz quando nos compreendemos nos ocupando como uma possibilidade de sermos, como presença. Os objetos, segundo Heidegger (2005), têm uma conformidade com, junto a, mas que isso não lhe determina o que ele é, e sim um "para-que”, uma utilidade, uma serventia.

Assim, quando usamos a fração, ela está em conformidade junto ao fracionar/dividir/localizar/relacionar, no que diz respeito ao seu poder-ser, ou seja, ela só é enquanto sendo na mundanidade. Destarte um objeto, ou a fração, como nosso exemplo, não tem uma definição a priori, mas sua determinação está relacionada ao horizonte de conformidade em que está imersa. Portanto, necessita de que alguém a faça, precisa-se de um ente que, ao ocupar-se dela, coloque-a no movimento da conformidade.

Foi possível observar, quando o grupo chegou à concordância de questionar: "é $\frac{1}{3}$ do quê?”, que os professores se abriram ao questionamento e à compreensão da necessidade de um ensino de Matemática imerso na comunicação entre pessoas, conhecimento e mundo.

\section{Reunindo alguns fragmentos: encaminhando uma conclusão}

Neste texto, tecemos considerações sobre a formação de professoras de Matemática dos Anos Iniciais, tendo o estranhamento como ponto de partida para questionamentos e compreensões de diversos significados que a fração pode assumir.

O episódio discutido neste artigo apresenta uma dessas personalidades da representação fracionária e um estilo de formação em que o professor é chamado para se formar a partir de suas próprias falas e inquietações. Afirmamos que, no encontro, no centro esteve o modo como o professor se dá conta de que aprende com seus pares.

$\mathrm{Na}$ reta final do momento de formação, retomando o acontecido no grupo de estudos, o escrutínio do depositado na urna pelas professoras no início do encontro nos possibilitou entender a relação parte-todo e a ideia de divisão como os principais significados atribuídos às frações.

Algumas das respostas à pergunta “o que é fração?" que permaneceram veladas durante o encontro apontam a dificuldade percebida na identificação de $\frac{1}{3}$ na reta numérica. São elas:

-É uma parte do inteiro, onde se reparte em partes iguais.

- A parte de um todo.

- É uma parte ou mais de um todo.

- Fração é uma parte de alguma coisa. Um pedaço de algo.

- Pedaços de um inteiro; parte de um todo, ou seja, uma divisão. 
-É a parte de um todo ou um número. (Respostas das professoras para a pergunta "O que é fração?", 2015).

Reconhecer distintas personalidades das frações ajuda professores a se preocuparem e se ocuparem com elas em situações diversas, atentos aos significados atribuídos para que o conhecimento vá se constituindo à medida que o sentido vai se fazendo.

No estilo de formação conduzido, assumimos que há imprevisibilidade, incertezas e angústias que podem até mesmo ser sistematizadas em determinado momento, mas jamais dadas em definitivo. Este movimento, de estar em condição de ser, é o traço da formação de professor: o dar-se conta de sermos professores, sendo. Essa incerteza abre-nos às possibilidades de um pensamento inédito, o da formação como o que se constitui nuclear em um professor: o movimento.

As formas delineadas pela ação empreendida, ao nos mantermos atentas aos modos como nos formamos com os outros, nossos alunos e pares de profissão, possibilita colocar em destaque o movimento formativo como produto que produz formas pela ação de quem está se formando.

Com o estudo, entendemos que a formação do professor de Matemática dos Anos Iniciais não é somente uma maneira de adquirir uma nova técnica didática; é mudar o modo de pensar. Essa mudança, ao mesmo tempo em que abre novas possibilidades, implica também uma perda. No dar-se conta de ser-com e ser-em formação o professor reorienta seu modo de pensar, sentir e conceber o mundo, dada a incerteza de aprender a cada dia a ser professor.

Por último, mas não por fim, esperamos que a exposição de um estilo de formação entre pares profissionais contribua com a ação docente e a postura investigativa de professores e pesquisadores interessados no ensino da Matemática nos Anos Iniciais, bem como contribua com as pesquisas sobre a formação de professores da Educação Básica, no âmbito da Educação Matemática.

\section{Referências}

BERTONI, N. E. Educação e Linguagem Matemática IV: Frações e Números Fracionários. Brasília: Universidade de Brasília, 2009.

BERTONI, N. E. Um novo paradigma no ensino e na aprendizagem das frações. In: ENCONTRO NACIONAL DE EDUCAÇÃO MATEMÁTICA, 8., Recife, 2004. Anais... Recife: SBEM, 2004.

BICUDO, M. A. V. Pesquisa qualitativa segundo a visão fenomenológica. São Paulo: Cortez, 2011.

BICUDO, M. A. V. Filosofia da Educação Matemática segundo uma perspectiva Fenomenológica. In: BICUDO, M. A. V. Filosofia da Educação Matemática: Fenomenologia, concepções, possibilidades didático-pedagógicas. São Paulo: UNESP, 2010. p. 23-46. 
BRASIL. Ministério da Educação. Secretaria de Educação Básica. Parâmetros Curriculares Nacionais: Matemática. Brasília, 1997.

CAMPOS, T. M. M.; MAGINA, S.; NUNES, T. O professor polivalente e a fração: conceitos e estratégias de ensino. Educação Matemática Pesquisa, São Paulo, v. 8, n. 1, p. 125-136, 2006.

CANOVA. R. F. Crença, concepção e competência dos professores do $1^{\circ}$ e $2^{\circ}$ ciclos do Ensino Fundamental com relação à fração. 2006. 220 f.. Dissertação (Mestrado em Educação Matemática) Programa de Estudos Pós-Graduados em Educação Matemática, PUC-SP, São Paulo, 2006.

CASANOVA, M. Linguagem cotidiana e competência existencial. Natureza Humana, São Paulo, v. 8, n. 1, p. 35-85, jan./jun. 2006. Disponível em: http://pepsic.bvsalud.org/pdf/nh/v8n1/v8n1a02.pdf. Acesso em: 3 jul. 2017.

CAVALCANTI, E. M. S.; GUIMARÃES, G. L. Os significados de fração em livros didáticos das séries iniciais. In: SIMPÓSIO INTERNACIONAL DE PESQUISA EM EDUCAÇÃO MATEMÁTICA, 2., 2008, Recife. Anais... Pernambuco: UFPE, 2008. p.1-12.

CUNHA, A. G. Dicionário etimológico da língua portuguesa. 4. ed. Rio de Janeiro: Lexikon, 2010.

DAMICO, A. Uma investigação sobre a formação inicial de professores de matemática para o ensino de números racionais no ensino fundamental. 2007. 313 f. Tese (Doutorado em Educação Matemática) - Pontifícia Universidade Católica de São Paulo, São Paulo, 2007.

ESTEVES, A. K.; SOUZA, N. M. M. de. Números Decimais na sala de aula: os conhecimentos de um grupo de professores e a relação com sua prática pedagógica. Revista Eletrônica de Educação, São Carlos, v. 6. n.1, p.188-205, mai. 2012. Disponível em:

http://www.reveduc.ufscar.br/index.php/reveduc. Acesso em: 10 mai. 2017.

GIMENES, J.; BAIRRAL, M. Frações no currículo do ensino fundamental: conceituação, jogos e atividades lúdicas. Seropédica: GEPEM/EDUR, 2005. 130p. v. 2. (Série Pensamento em Ação).

HEIDEGGER, M. Ser e Tempo. Tradução de Marcia Sá Cavalcante Schuback. 15. ed. Petrópolis-RJ: Vozes, 2005.

LINS, R. C., SILVA, H. Frações. Fascículo 4, In: BRASIL. Pró-Letramento: Programa de Formação Continuada de Professores dos Anos/Séries Iniciais do Ensino Fundamental : matemática. Secretaria de Educação Básica - Brasília: Ministério da Educação, Secretaria de Educação Básica, 2008. p. 08 39.

LONGARETTI, M. Conhecimento e educação matemática: diálogos. 2005. 479 f. Dissertação (Mestrado em Educação) - Universidade Federal do Paraná, Curitiba, 2005.

MERLINI, V. L. O conceito de fração em seus diferentes significados: um estudo diagnóstico com alunos de $5^{\mathrm{a}}$ e $6^{\mathrm{a}}$ séries do Ensino Fundamental. 2005. 238 f. Dissertação (Mestrado em Educação Matemática) - Pontifícia Universidade Católica São Paulo, São Paulo, 2005.

MOCROSKY, L. F. et al. Reunindo fragmentos: as frações na formação de professores dos anos iniciais. In: SIMPÓSIO NACIONAL DE ENSINO DE CIÊNCIA E TECNOLOGIA, 5., 2016, Ponta Grossa, PR. Anais.... Ponta Grossa: UTFPR, 2016, p.1 - 11.

MOREIRA, P .C. O conhecimento matemático do professor: formação na licenciatura e prática docente na escola básica. 2004. 195f. Tese (Doutorado em Educação) - Faculdade de Educação, Universidade Federal de Minas Gerais, Belo Horizonte, 2004. 
NUNES, T.; BRYANT, P. Crianças fazendo Matemática. Porto Alegre: Artes Médicas, 1997.

NUNES, T.; CAMPOS, T.; MAGINA, S.; BRYANT, P. Educação matemática: números e operações. São Paulo: Cortez, 2009.

ONUCHIC, L. R.; ALLEVATO, G. As diferentes "personalidades" do número racional trabalhadas através da resolução de problemas. Bolema, Rio Claro, v. 21, n. 31, p. 79-102, 2008.

RERIDA MARIA. Atividade com Fração. 2014. Disponível em: http://reridamaria.com.br/?p=2319. Acesso em: 4 jan. 2016

ROMANATTO, M. C. Número Racional: relações necessárias a sua compreensão. 1997. 169 f. Tese (Doutorado em Educação Matemática) - Faculdade de Educação, Universidade Estadual de Campinas, Campinas, 1997.

ROMANATTO, M. C. Número racional, uma teia de significações. Zetetiké, Campinas, v. 7, n. 12, p. 37-49, jul./dez. 1999.

SILVA, J. F. S. Investigando saberes de professores do ensino fundamental com enfoque em números fracionários para a quinta série. 2005. 302 f. Tese (Doutorado em Educação Matemática) - Pontifícia Universidade Católica São Paulo, São Paulo, 2005.

ZONTINI, L. R. S. O Pró-Letramento em Matemática: compreensões do professor-tutor sobre ideias que sustentam o ensino da matemática nos anos iniciais. 2014. 328 f. Dissertação (Mestrado em Educação em Ciência e em Matemática) - Universidade Federal do Paraná, Curitiba, 2014.

Submetido em 18 de Dezembro de 2018. Aprovado em 13 de Junho de 2019. 